\title{
Reducing Paper Use through Wider Deployment of New Office Technologies in Business Organizations in Enugu Capital City, Nigeria
}

\author{
*Okoye H.I. \& **Obi C.A. \\ *Postgraduate Research Scholar, Department of Vocational Teacher Education, University of Nigeria, Nsukka \\ **Professor of Business Education, Department of Vocational Teacher Education, University of Nigeria, \\ Nsukka
}

\begin{abstract}
The myth of green and paperless office may still be with us but there are today new technologies corporate organizations can deploy to significantly reduce paper use in order to cut cost and become more environmentally-friendly. This study determined the extent organizations in Enugu Capital City deploy new office technologies for reducing paper use. The population comprised 186 employees made up of 130 office managers and 56 IT professionals. The entire population was used. The instrument was a structured questionnaire validated by three experts while reliability was established using Chronbach Alpha which yielded a high reliability co-efficient of 0.87 . Two research questions were formulated to guide the study. Data collected were analyzed to answer the research questions using mean and standard deviation, while z-test was used to test two null hypotheses at 0.05 level of significance. The major findings of the study showed that the organizations still rely heavily on physical paper instead of deploying new office technologies to reduce paper use. Based on the findings, it was recommended, inter-alia, that business organizations should, as matter of policy, take concrete steps to convert their paper documents to electronic platforms for economy, greater efficiency, and greener environment.
\end{abstract}

Key words: deployment, green environment, medium-sized organizations, new technologies, paper, paper use.

\section{Introduction}

A paper is a material made of cellulose pulp, derived mainly from wood, rags, and certain grasses, processed into flexible sheets or rolls by deposit from an aqueous suspension. It is used chiefly for writing, printing, drawing, wrapping and covering walls. Paper is also simply defined as a piece of material containing a written or printed statement or document (Dictionary.com, 2013).The word "deployment" refers to the action of using; to put to service or apply for a purpose (Meriam-Webster, 2013). Paper, according to Confederation of Paper Industries (2013) is used in different categories of business organizations (micro, small, medium and large) to print various types of document, for example, spread sheets, receipts, circulars, catalogues, sales and service manuals, brochures, letters, envelopes, minutes and reports.

Medium-sized business organizations are entities with capital of between one hundred and three hundred million Naira, with a workforce of between 71 and 200 full time staff and/or a turnover of not more than twenty million Naira (Obi, 2011). However, according to Salami (2003), each country tends to define sizes of businesses based on the role organizations play in the economy. Thus, a firm regarded as small in a developed economy may be classified as medium in developing countries like Nigeria and Ghana. The particular category (medium-sized business organizations) was chosen for this study because it lies between the large-scale and micro/small enterprises and also is expected, by size, to possess and adequately utilize new office technologies.

Technology refers to the study, development, and (scientific) application of devices, machines and techniques for productive purposes. New office technologies are therefore the modern, advanced and sophisticated ones, including software, widely applied by employees in carrying out office functions. These new sophisticated technologies with their advanced capabilities, user-friendly software and competitively low prices are supposed to be accessible to most workplaces ranging from manufacturing and service to most public organizations (Microsoft Encarta, 2009; Okoye, 2012).

Managers and IT professionals work in business organizations. Managers are usually in the middlelevel line of responsibilities and are charged with the duties of setting objectives, organizing work, motivating and communicating, measuring performance and developing people (Lehman, 2007). IT professionals are those specially trained in the field of information technology and who provide support services in hardware, software and shareware development, maintenance, supplies and services (Pirillo, 2007). As persons in charge of men and materials, managers and IT professionals have responsibilities of ensuring efficient utilization of resources, including new office technologies. 
A recent empirical research by Reduce.org (2013) showed that, through the deployment of new technologies and website development, a Minneapolis-based organization achieved 22\% paper reduction together with $\$ 7000$ annual savings on copying and printing costs. Increased perception of its customers as being environmentally friendly also continued to drive its efforts to expand its web-based activities towards the achievement of green office. The research, sponsored by Minnesota Pollution Control Agency, and also corroborated by a publication by Standard Chartered Bank (2010), recommended a model for paper reduction called the " 3 Es". The " 3 Es" stand for: Economical, Environmentally-friendly and Efficient. Economical implies that saving paper means saving money. Costs associated with paper could be as much as 31 times the purchasing cost, not counting labour. A ream of paper one buys at N500.00 (Nigerian local currency) for instance, can really cost up to N15,500.00 because each sheet used incurs cost in storage, toner, printing, maintenance, depreciation, energy consumption, postage, disposal, and recycling. According to Hilary and Gunderson (2009), environmental cost results from the fact that paper is created from trees which require a lot of natural resources: water and energy. It takes more than $1 \frac{1}{2}$ cups of water to make one paper and reducing paper use reduces greenhouse gases. Everyone is today talking "green" - green jobs, green energy, green farming, green cars, and green construction. Corporate organizations are joining the green revolution launching initiatives designed to reduce paper consumption and lessen impact of paper manufacturing on the environment. In terms of being efficient, reducing paper use will lead to fewer sheets of paper in organizations and less time spent in looking for those misplaced or lost.

Again, a study by Al-Qhatani (2012) revealed that the use of tablet devices and iPad in particular can be deployed to reduce paper use. Also email, Internet, Intranet and scanners radically reduce paper use, while saving time and money. Promoting e-billing and redesigning customer statements to use less paper equally save costs of printing and mailing bulky mail.

However, many offices still tend to rely on paper for everyday activities despite the high cost, risk of document loss or obsolescence and labour inefficiency. Thornton (2009) in Global-Stewards (2012) warned that, if not carefully handled, paper is becoming a clear impediment to organizations that are embracing greener IT. The good news, nevertheless, is that most papers used in today's offices have chances of being converted to electronic alternatives. Developing and implementing a successful paper reduction plan that meets the needs of multiple stakeholders does not come without challenges. It has been clearly established that, identifying the areas of the business with the greatest paper demand clarifies where paper reduction efforts and goals should focus. While Grandzol and Grandzol (2006), Stopwaste.org (2009) and Reid (2011) point to the same fact, Cities Management Inc (CMI) actually monitored paper use in three areas of photocopying, printing/faxing and mailing. The result is replicated in Table 1.

Table 1: CMI - Progress Made in Paper Use Reduction (June - Nov 2000 \& June - Nov 2001)

\begin{tabular}{|c|c|c|c|}
\cline { 2 - 4 } \multicolumn{1}{c|}{} & June - Nov. 2000 & June - Nov.2001 & Rate of Change \\
\hline Photocopying & 220,223 sheets & 222,983 sheets & $+2,760$ sheets $(+1 \%)$ \\
\hline Printing/Faxing & 35,931 sheets & 28,154 sheets & $-7,777$ sheets $(-22 \%)$ \\
\hline Mailing & 86,713 pieces & 60,185 pieces & $-26,528$ pieces $(-31 \%)$ \\
\hline
\end{tabular}

Source: CMI \& Agribank Demonstration Project Report, 2002.

Given the scenario therefore, there is need for modern business organizations to embrace the new technologies and to provide encouragement to employees on how to effectively deploy them to reduce paper use, save cost, save the environment and generally operate more efficiently. The extent business organizations in Enugu capital territory have embraced the new technologies to reduce paper use needed to be investigated and, consequently, attracted the researchers' attention.

\section{Statement of the Problem}

Existing literature reviewed clearly exposed the fact that business organizations should make concrete efforts to reduce paper use. In the United States of America alone, according to Reduce.org (2013), the number of paper documents generated is growing at the rate of 22 percent per year. About 50 million tons of paper is used each year, that is, 850 million trees. Of all the pages of paper handled each day in an average office, 90 percent are merely shuffled. In California, businesses generate 47 percent of the waste stream, and paper is the second largest component. This is in spite of the much talked about e-world and paperless or green office. The production of paper takes an enormous environmental toll, significantly reducing forests, emitting toxic pollution from production processes, and contributing a greater quantity of paper products to landfills (CMI \& Agribank Report, 2002; Stopwaste.org, 2009; Global-Stewards, 2012; Confederation of Paper Industries, 2013; and Standard Chartered Bank Report, 2010). Therefore, organizations by reducing paper use will not only save money, become efficient but also come out top as better corporate citizens. The story about high paper use is apparently true in other climes including Enugu Capital City in particular and Nigeria in general. The problem 
of this study is therefore to determine the extent enormous use of paper has been reduced by medium-sized business organizations in this era of new office technologies.

\section{Purpose of the Study}

The purpose of the study was to find out the extent medium-sized business organizations in Enugu Capital City are reducing paper use through wider deployment of new office technologies. Specifically the study sought to determine:

1) the extent paper is currently being used in medium-sized business organizations in Enugu Capital City.

2) the extent new office technologies are being deployed to reduce paper use in medium-sized business organizations in Enugu Capital City.

\section{Research Questions}

1) To what extent do medium-sized business organizations in Enugu Capital City currently use paper?

2) To what extent do medium-sized business organizations in Enugu Capital City currently deploy new office technologies to reduce paper use?

\section{Null Hypotheses}

$\mathrm{Ho}_{1}$ There is no significant difference in the mean ratings of office managers and IT professionals on the extent medium-sized business organizations use paper.

$\mathrm{Ho}_{2}$ There is no significant difference in the mean ratings of office managers and IT professionals on the extent medium-sized business organizations deploy new office technologies to reduce paper use.

\section{Methodology}

Survey research design was adopted since the purpose was to obtain data by use of questionnaire. Survey design centers on people, their opinions, attitude and behaviour. It is not manipulative but studies and records opinions or observations by use of questionnaire or rating scales (Osuala, 2004; Osondu and Abugu, 2008). The study was carried out in Enugu Capital City which comprises Enugu North, Enugu South and Enugu East Local Government Councils. It was recently observed that the thriving spirit of enterprise among the high population of erudite business men and women, coupled with fully developed industrial infrastructure, make Enugu a business center of Eastern Nigeria (Enugu Chamber of Commerce, Industry, Mines \& Agriculture [ECCIMA], 2013). Enugu was, therefore, considered suitable as the area of study. The population for the study consisted of 186 respondents (130 office managers and 56 IT professionals) in 22 medium-sized organizations in Enugu Capital City. Organizations were in the list of ECCIMA (2013). The entire population was studied.

Two research questions and two hypotheses guided the study. Data were collected using a 35-item structured questionnaire developed from the literature reviewed and titled "Paper Use Reduction Questionnaire (PURQ)". The instrument carried a five-point scale of: Very Great Extent (5), Great Extent (4), Moderate Extent (3), Low Extent (2) and Very Low Extent (1). The instrument was validated by three experts - one Information Technology professional and two lecturers from the School of Business Education, Enugu State College of Education (Technical). The reliability was established using Chronbach Alpha which yielded reliability coefficient of 0.87. Mean and standard deviation were used to analyze the scores and answer the research questions, based on real limit of numbers. For purposes of interpretation, the mean ratings were given as follows: 4.50 and above $=$ Very Great Extent $(\mathrm{VGE}) ; 3.50-4.49=$ Great Extent (GE); $2.50-3.49=$ Moderate Extent; $1.50-2.49=$ Low Extent (LE); and $0.50-1.49=$ Very Low Extent (VLE). The z-test was used to test the null hypotheses. A null hypothesis was not rejected if the $\mathrm{z}$-calculated was less than $\mathrm{t}$-table of $+/-1.96$ at 0.05 level of significance; otherwise the hypothesis was rejected.

III. Results

The results are presented in line with the research questions and hypotheses that guided the study.

Table 2: Mean Score, Standard Deviation and z-test Analysis of the Respondents' Ratings of the Extent of Paper Use by Medium-sized Organizations

\begin{tabular}{|c|c|c|c|c|c|c|c|c|c|}
\hline \multirow[t]{2}{*}{$\begin{array}{c}S / N \\
o \\
\end{array}$} & \multirow[t]{2}{*}{ Paper Use } & \multicolumn{2}{|c|}{$\begin{array}{c}\text { Office } \\
\text { Managers }\end{array}$} & \multicolumn{2}{|c|}{$\begin{array}{c}I T \\
\text { Professionals } \\
\end{array}$} & & \multirow[t]{2}{*}{ Rmks } & \multirow[t]{2}{*}{$z-c a l$} & \multirow[t]{2}{*}{ Rmks } \\
\hline & & $\mathbf{X}_{1}$ & SD $_{1}$ & $\mathbf{X}_{2}$ & $\mathbf{S D}_{2}$ & $X G$ & & & \\
\hline 1 & Notices, memo pads, letter heads and envelopes & 4.28 & 0.75 & 4.43 & 0.69 & 4.36 & GE & -1.04 & NS \\
\hline 2 & Newsletters and In-house Magazines & 4.17 & 0.93 & 4.36 & 0.80 & 4.27 & GE & -0.47 & NS \\
\hline 3 & Notepads and sticky notes & 4.08 & 0.90 & 4.29 & 0.79 & 4.19 & GE & -1.24 & NS \\
\hline 4 & Business cards & 4.23 & 0.73 & 4.38 & 0.68 & 4.30 & GE & -1.06 & NS \\
\hline 5 & Annual calendars and Diaries & 4.37 & 0.64 & 4.52 & 0.62 & 4.44 & GE & -1.18 & NS \\
\hline 6 & Training manuals & 4.08 & 0.92 & 4.27 & 0.84 & 4.17 & GE & -0.85 & NS \\
\hline
\end{tabular}




\begin{tabular}{|c|c|c|c|c|c|c|c|c|}
\hline 7 & $\begin{array}{l}\text { Weekly, monthly and annual reports (department } \\
\text { and organization-wide) }\end{array}$ & 4.17 & 0.93 & 4.36 & 0.80 & 4.26 & GE & -0.47 \\
\hline 8 & Marketing brochure, manuals and handbills & 4.23 & 0.73 & 4.38 & 0.68 & 4.30 & GE & -1.06 \\
\hline 9 & Vendor contract papers & 4.28 & 0.75 & 4.40 & 0.75 & 4.34 & GE & -0.79 \\
\hline 10 & Supplier Invoices and Delivery Notes & 4.23 & 0.83 & 4.29 & 0.76 & 4.26 & GE & -0.38 \\
\hline 11 & Budgets and financial statements & 3.69 & 1.07 & 3.72 & 1.01 & 3.70 & GE & -0.14 \\
\hline 12 & Byelaws, articles, procedures and regulations & 3.94 & 0.99 & 3.95 & 1.01 & 3.94 & GE & -0.05 \\
\hline 13 & $\begin{array}{l}\text { Workers' Handbook (Conditions of Service) and } \\
\text { other personnel forms }\end{array}$ & 3.73 & 1.07 & 3.81 & 0.99 & 3.77 & GE & -0.39 \\
\hline 14 & Agenda and minutes of meetings & 3.78 & 1.02 & 3.90 & 0.91 & 3.84 & GE & -0.62 \\
\hline 15 & Maintenance requests or work orders & 3.76 & 1.02 & 3.88 & 1.03 & 3.82 & GE & -0.58 \\
\hline
\end{tabular}

$N B: X_{1}=$ Mean 1; $X_{2}=$ Mean 2; $S D_{1}=$ Standard Deviation 1; $S D_{2}=$ Standard Deviation 2;

$X G=$ Grand Mean; Rmks = Remarks; GE = Great Extent $;$ NS = Not Significant

Table 1 shows that all the items had their grand means ranging from 3.70 to 4.44 . This implied that all the types of paper documents are used to a great extent by the medium-sized business organizations. The table also indicates that all the items had their z-value less than z-table of 1.96 at 0.05 level of significance. This means that there were no significant differences in the mean ratings of office managers and IT professionals on the extent of paper use by the business organizations.

\section{Table 3: Mean Score, Standard Deviation and z-test Analysis of the Respondents' Ratings of the Extent of Deployment of New Technologies by Medium-sized Organizations to Reduce Paper Use}

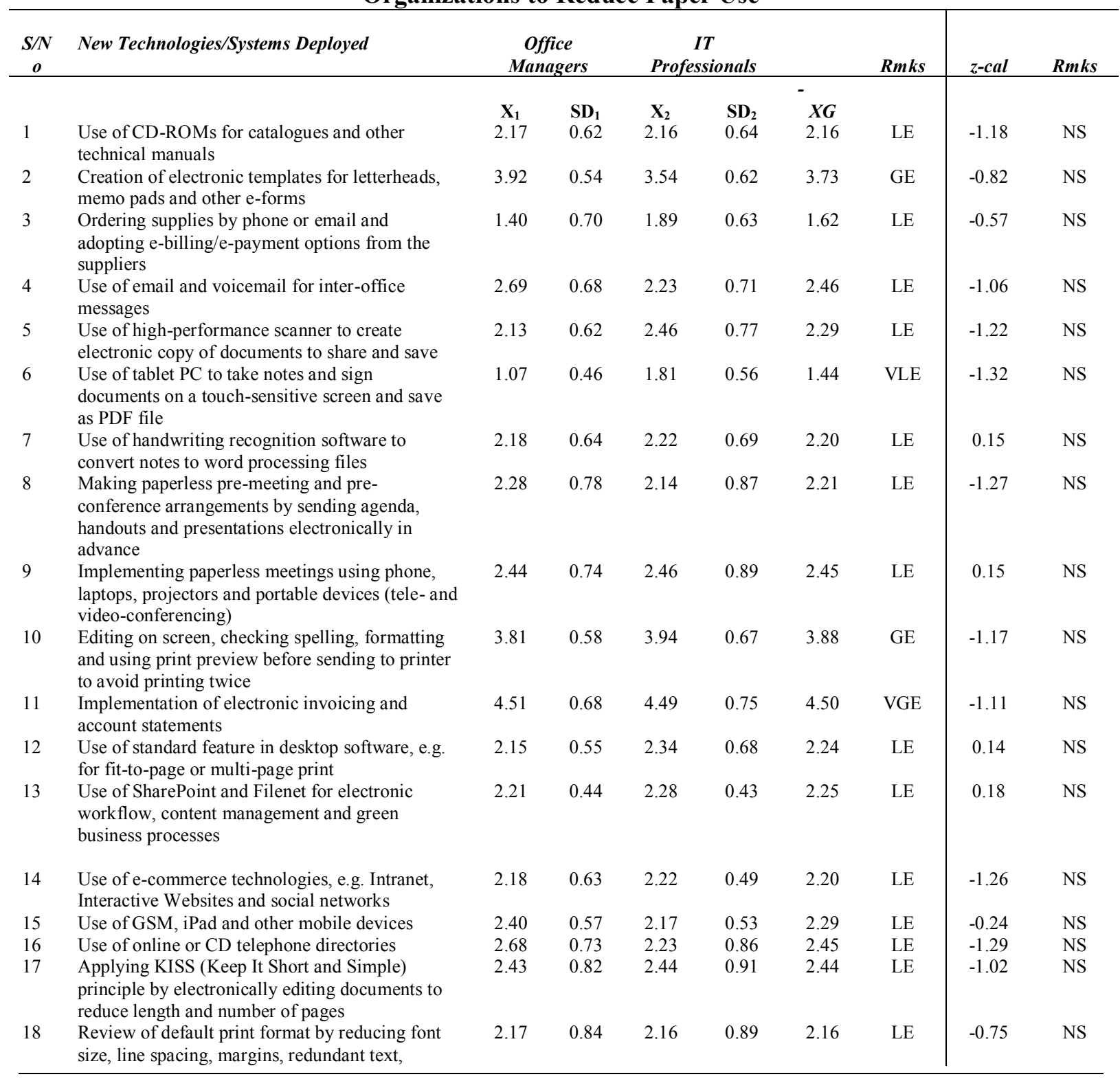


header/footer or multiple slides per page (for slide presentations)

19 Installation of multi-function devices that can print, scan and copy

20 Installation of fax gateway solution, duplex enabled printers and wireless Local Area Network (LAN)

NB: $X_{1}=$ Mean 1; $X_{2}=$ Mean 2; $S D_{I}=$ Standard Deviation 1; $S D_{2}=$ Standard Deviation 2; $X G=$ Grand Mean; Rmks = Remarks; VGE = Very Great Extent; GE = Great Extent; $L E=$ Low Extent; VLE = Very Low Extent; NS $=$ Not Significant

Table 2 indicates that item 11 (implementation of electronic invoicing) had a grand mean of 4.50, meaning that new technologies are deployed to a very great extent in that area. It also revealed grand means of 3.73 and 3.88 for items 2 and 10 showing that new technologies are deployed to a great extent in the two areas of creating templates and editing on screen before printing. Conversely, 16 items out of the entire 20 skewed negatively to show that new technologies are deployed to a low extent (their grand means ranging from 1.62 to 2.46). Item 6 even showed deployment to a very low extent with a grand mean of 1.44. However, the Table indicates that all items had their z-value less than z-table of $+/-1.96$ at 0.05 level of significance. This implies that there were no significant differences in the mean ratings of the two groups of respondents on the extent of deployment of the new technologies by business organizations.

\section{Discussion of the Findings}

The findings of the study revealed that business organizations in Enugu Capital City still use many types of paper to a great extent for their daily activities in the office. These types of paper include, among others, routine mail such as notices, memos, letterheads and envelopes. Others are notepads and sticky notes; business cards; annual calendars and diaries, reports of different kinds; brochures, supplier invoices, agenda and minutes of meetings. This is in line with the views of Stopwaste.org (2009), Reid (2011), and Global-Stewards (2012) that organizations still rely heavily on paper to perform everyday duties, despite the high costs associated with lost documents, risk of obsolescence, labour inefficiency and environmental pollution.

The findings also showed that the respondents agreed that new technologies were deployed to a very great extent by the organizations only in the area of implementing electronic invoicing and accounts statements; and to a great extent for creating templates and editing on screen before printing. According to the respondents, new technologies were deployed to a low extent in 16 areas, among which are: use of CD-ROM for catalogues; email and voice mail; high performance scanner; handwriting recognition software; sharepoint and filenet; ecommerce technologies; multi-function devices; and gateway solutions. The research findings equally revealed that tablet PC was deployed to a very low extent for taking notes and signing documents (on a touch-screen) to be saved in a PDF file. Again, there was agreement between the two groups of respondents on the extent of paper use and deployment of new technologies to reduce the paper use. This was shown by no much dispersion in their standard deviations and the z-values which were less than z-table of $+/-1.96$ at 0.05 level of significance. The overall picture indicated that new technologies were not adequately being deployed by the business organizations to reduce paper use. The organizations were still steeped in the deployment of old equipment and methods that involve the use large volume of paper. This agrees with the opinion of Bothma and Hoffman (2008) that traditionally, manual equipment, paper documents, folders and filing cabinets were still being used. This system was considered by the authors as expensive, requiring extensive space in corporate offices, as well as excessive human resources to maintain them in a well-structured and sustainable process.

\section{Conclusion and Recommendations}

Business organizations are not adequately deploying new office technologies to reduce paper use. This is contrary to the views of Bothma and Hoffman (2008) that, in a contemporary global information and communication technology interface in business administration, there is a magnitude of information that needs to be managed in a manner that could exceedingly improve the outdated, tiresome, expensive and timeconsuming processes and procedures. Business organizations in this new era therefore need to embrace modern office technologies for reducing paper use, cutting cost, achieving green environment, and promoting good corporate citizenship. Based on the foregoing, therefore, it was recommended that:

1. Business organizations, particularly ones in Enugu Capital City, should conduct an audit of their current paper consumption rate in their different departments with a view to setting realistic, measurable targets and applying best practices, aligned to their specific nature of business, to reduce paper use.

2. Organizations should acquire and deploy adequate new office technologies and network systems identified by this research, and deploy them to reduce paper use. 
3. They should take concrete steps to gradually convert their different types of paper documents to electronic alternatives or versions and make effective use of CD-ROMs for sending reports to stakeholders like shareholders and Board members.

4. Business offices should equally make more use of e-forms, and re-design other business forms electronically, to reduce length and number of pages for the ones they must print.

5. Managers and IT professionals in organizations should put in place the necessary policies and procedures, train their personnel, and show example by personally deploying new technologies to reduce paper use.

\section{References}

[1] Dictionary.com (2013). Paper definition. Random House Inc. Available @ http://dictionary.reference.com/browse/paper.

[2] Merriam-Webster Online Dictionary (2013). Merriam-Webster Incorporated. Available @ http://www.merriamwebster.com/dictionary/deployment.

[3] Confederation of Paper Industries (2013). Paper and its uses - fact sheet. Retrieved from http://www.paper.org.uk on 02/05/2013.

[4] Obi, C.A. (2011). Elements of Business. $3^{\text {rd }}$ ed. Enugu: De-Verge Agencies Ltd.

[5] Microsoft Encarta (2009). Technology. Microsoft Incorporation.

[6] Okoye, H.I. (2012). Quality assurance and new technologies in Office Technology and Management Education. A paper presented at the 24th Annual National Conference of the Association of Business Educators of Nigeria (ABEN). Owerri: 16 - 20 October.

[7] Lehman, L.B. (2007). Supervisor or manager: what is in a name? Rising Sun Consultants Ltd. Retrieved from www.risingsundconsultants.com on 10/01/2013.

[8] Pirillo, C. (2007). What is your definition of IT professionals? Lockergnome, Inc. Available @, http://lockergnome.com/it/2007/08/06. Retrieved on 08/05/2013.

[9] Reduce.org (2013). Become a paperless office. Minnesota Pollution Control Agency. Retrieved from http://156.98.19.245/paper/\#3Es on 20/03/2013.

[10] Standard Chartered Bank (2010). Reducing and eliminating paper consumption: a best guide for corporate offices. Shangai: Edition 1, May.

[11] Hilary, T.M. and Gunderson, C. (2009). Reducing paper use saves money ... and maybe even the planet. Peoria Magazines. Central Illinois Publishers Inc., March.

[12] Al-Qahtani, S.H. (2012). The paperless organization: improved processes and reduction in paper usage through wider use of electronic documents and tablet computers. M.Sc. Thesis. New Zealand: University of Waikato.

[13] Thornton, C. (2009). IBM helps clients reduce costs associated with paper consumption. IBM Media Relations. Downloaded from http://ibm.com/us/en on 06/05/2013.

[14] Global-Stewards (2012). Create a paperless office: reduce paper use and increase productivity. Available @ http://www.globalstewards.org/index.htm..

[15] Grandzol, J.R. \& Grandzol, C.J. (2006). Best practices for online business education. Canada: The International Review of Research in Open and Distance Learning, 7(1). Athabasca University.

[16] Stopwaste.org (2009). Paperless express - a paper use reduction guide for your business. California Integrated Waste Management Board. Retrieved from http://www.stopwaste.org/paperless-office/...

[17] Reid, R. (2011). Initiatives to reduce paper use and improve the bottom line. Canada: Environmental Leader (Energy Manager News). Available @ http://environmentalleader.com/2011/01/11/initiatives-to-r... Retrieved on 12/05/2013.

[18] Cities Management Inc. \& Agribank (2002). Office paper reduction demonstration project - final report. Richfield: Solid Waste Management Co-ordinating Board. February.

[19] Osuala, E.C. (2004). Introduction to Research Methodology. Onitsha: Africana Feb Publishers Ltd.

[20] Osondu \& Abugu (2008). Research Methodology. Enugu: Lano Publishers Ltd.

[21] Enugu Chamber of Commerce, Industry, Mines \& Agriculture (2012). Catalogue. A publication on the $24^{\text {th }}$ Enugu International Trade Fair. March $15-25$.

[22] Bothma, M.M. \& Hoffman, E.C. (2008). Combating the corporate paper war: electronic mail abuse. Department of Information \& Knowledge Management, University of Johannesburg. Interword Communications. 10(1). March. 